\title{
0 solipsismo como forma extrema de ceticismo no Século das Luzes
}

\author{
Sébastien Charles \\ Université de Sherbrooke \\ sebastien.charles@usherbrooke.ca
}

resumo Este artigo visa mostrar a persistênc ia, no século XVIII, de um problema nascido em solo cartesiano - o solipsismo - a fim de atenuar a distinção demasiado abrupta que habitualme nte se faz entre o racionalismo clássico e o empirismo das Luzes, particularmente em nível epistemológico. Depois de mostrar a importância do debate do século XVIII e de repertoriar os argumentos pró e contra a posição solipsista, o artigo se conclui com uma defesa de uma releitura da filosofia das Luzes e propõe-se a vincular o pessimismo epistemológico que caracteriza as grandes teorias filosóficas do final do século XVIII à persistência do cartesianismo em um século que todavia se acreditava livre do espírito de sistema do século precedente.

palavras-chave Cartesianismo; solipismo; racionalismo; filosofia das Luzes

Quando nos atemos a uma generalização grosseira que permite opor, de maneira suficientemente categórica, a filosofia do século XVII, idealista e sistemática, à filosofia do XVIII, empirista e menos ciosa de sistematicidade metódica, esquecemo-nos com freqüência de que alguns dos problemas metafísicos mais importantes da era moderna tenderam a se perpetuar no Século das Luzes. Opondo-se em demasia, como faz o próprio Condillac na introdução do Ensaio sobre a Origem dos Conhecimentos Humanos, a velha metafísica, ambiciosa e errônea, à nova, ciosa dos limites do entendimento humano e bem proporcionada aos seus objetos de estudo, perde-se de vista o essencial - a saber, que, embora apreendidos de outro modo e tratados de modo diverso, são os mesmos problemas

Recebido em 07 de julho de 2007. Aceito em 12 de outubro de 2007.

Tradução: Luiz Alves Eva.

doispontos, Curitiba, São Carlos, vol. 4, n. 2, p.13-38, outubro, 2007 


\section{4}

metafísicos que se põem com um século de distância. Dentre eles, talvez o mais importante é o que concerne à demonstração da existência do mundo exterior e que estimulará tanto a especulação dos filósofos das Luzes quanto a dos pensadores do século precedente.

Depois de rapidamente apresentar a emergência dessa questão no contexto cartesiano, mostrarei como ela mobilizou a inteligência dos filósofos das Luzes e quais são os argumentos que, parecendo-lhes demonstrativos, utilizaram para respondê-la, através de uma exposição dos contra-argumentos propostos à época. Destacarei, de passagem, que a questão solipsista é indissociável do ceticismo, o que me permitirá mostrar, ao final, a fecundidade do cartesianismo em um século que dele pretendeu, não obstante, libertar-se e a dificuldade que tiveram os pensadores das Luzes para se libertar do ceticismo, o que explica, a meu ver, o pessimismo epistemológico que caracteriza as grandes teorias filosóficas do fim do século, assombradas por um probabilismo que parece indicar que a certeza é mais uma questão de graus do que de natureza.

\section{A emergência do problema da existência do mundo exterior em terra cartesiana}

Antes de Descartes, a questão da demonstração da existência do mundo exterior não se põe verdadeiramente. ${ }^{1}$ Com efeito, pretendendo inverter a ordem das certezas e fazer, pelo viés da descoberta do cogito, com que a certeza da existência da alma seja mais imediata do que a do corpo, é Descartes quem pôs o problema da demonstração da existência do mundo exterior. Essa não era, por certo, sua intenção principal: ele tinha tanta certeza da existência do corpo quanto da alma, sendo a certeza do cogito apenas metodologicamente primeira na ordem dos conhecimentos. Pois, para Descartes, a existência necessária de um Deus bom garante de maneira definitiva que as sensações que percebemos remetem verdadeiramente a algo de existente fora de nós, mesmo que não nos permitam conhecer sua natureza ${ }^{2}$ - a extensão, como substância, seria compreensível apenas pelo entendimento.

Para os contemporâneos de Descartes, essa solução ao problema da existência dos corpos exteriores, por mais engenhosa que fosse, não 
resolvia em absoluto a questão. Regius, por exemplo, considerava que Deus podia ter boas razões para nos enganar (para nosso bem, ou mesmo para nos punir dos pecados). E mesmo que não fosse enganador, ele podia sem dificuldade nos afetar da mesma maneira, com ou sem matéria. Em resumo, para Regius, sem a fé que evoca a criação do universo, a existência do mundo exterior permanece problemática. É a solução que Malebranche retoma, fazendo da fé a única garantia da objetividade do mundo. Apesar da crítica de Arnauld, desenvolvida no capítulo 28 das Idéias Verdadeiras e Falsas, é a posição de Malebranche que prevalecerá.

O abade de Lanion, nas suas Meditações sobre a Metafísica, publicadas no ano de 1678, em Paris, sob o pseudônimo de Guillaume Wander, levaria o malebranchismo, e mais particularmente a tese sobre a simplicidade das vias, ao seu limite: "Deus, que age sempre pelas vias mais simples, sendo a causa imediata das minhas modificações, posso pensar que seria um desvio demasiado longo para tal ser infinitamente sábio a criação da extensão para me dar sensações que ela não pode produzir."3 O raciocínio é bem ponderado. Com efeito, para que serve a criação da matéria se Deus é capaz, sem ela, de produzir em nós modificações exatamente similares àquelas que nós teríamos se ela existisse? O resultado é que Lanion concede ele também que a fé garante a existência dos corpos externos, mas ele acrescenta que um tal ato de fé vai de encontro às deduções da razão e faz dessa existência um puro mistério. É igualmente a opinião de um professor de filosofia paduano, Michelangelo Fardella, que chega ao ponto de mostrar que a fé talvez não seja um critério de certeza exemplar pois a Santa Escritura possui diferentes sentidos e seria possível, assim, que as passagens nas quais ela menciona a existência dos corpos sejam destinadas apenas aos iletrados e não aos filósofos. ${ }^{4}$ Idéia compartilhada, na Inglaterra, por John Norris, que se recusa igualmente a ver no texto revelado uma prova demonstrativa da mesma existência dos corpos, uma vez que todo texto é, em si, um fragmento de matéria.

Outro problema que se põe em contexto cartesiano e que Simon Foucher, próximo do ceticismo acadêmico, bem notou é a grande distinção cartesiana entre qualidades secundárias e primárias. ${ }^{5}$ Se os cartesianos reconhecem que a percepção de qualidades secundárias provém do sujeito, eles deveriam igualmente aceitar o reconhecimento 
de que as qualidades primárias são também subjetivas. Esta intuição, como se sabe, foi retomada por Bayle no famoso artigo "Pirro" de seu Dicionário Histórico e Crítico; associada a um argumento muito interessante, ela conduz à inversão da tese cartesiana da veracidade divina. ${ }^{6}$ Com efeito, se os homens pensaram, desde o início da humanidade, que as qualidades ditas secundárias são inerentes aos objetos sem que isso tenha sido compreendido como uma ilusão divina, por que as coisas hoje as coisas se passariam de outro modo com as qualidades primárias? Ou, para dizê-lo nas palavras de Bayle: "Desde o começo do mundo, todos os homens, excetuando-se talvez um em duzentos milhões, crêem firmemente que os corpos são coloridos, o que é um erro. Eu pergunto: Deus engana os homens com respeito às cores? Se ele os engana em vista disso, nada impede que ele os engane em vista da extensão"(BAYLE, 1820, t. XII, art. Pyrrhon, p.102). A este interessante argumento Bayle acrescenta, no artigo "Zenão", a tese, tomada de Lanion, da simplicidade das vias. A fé não poderia garantir a existência do mundo exterior? Não, pois Bayle sabe que o argumento da fé cai na armadilha da circularidade: a fé não pode provar a existência dos corpos, pois o texto revelado é ele mesmo um corpo material, o que exige que se suponha o que está em questão.

Em resumo, no momento em que se termina um século e começa outro, o solipsismo parece surgir como uma posição filosófica coerente, mesmo legítima. Dele encontram-se traços em um manuscrito clandestino do início do século XVIII - as Reflexões morais e metafísicas sobre as religiões e os conhecimentos do homem ${ }^{7}$ - e nas revistas eruditas da época que reperatem o debate. ${ }^{8}$ Aparecem, assim, nas Memórias de Trévoux de 1704-1705, duas violentas diatribes contra o cartesianismo, que dele fazem uma porta de entrada inevitável para o solipsismo e uma causa possível do sucesso do ateísmo (porquanto o solipsismo arruína a prova cosmológica da existência de Deus) ao acusá-lo de tornar as disputas metafisicas modernas estéreis e de afastar, assim, os livre pensadores da simplicidade da religião cristã.

Assim, o cartesianismo, tomado como a panacéia ideal para estancar as especulações céticas, acabou apenas, mesmo na opinião de seus partidários, reforçando a dúvida mais radical de todas, a que se volta sobre a existência de todas as coisas, e não produziu, segundo o juízo dos seus detratores, nenhuma prova demonstrativa que permitisse resolver os 
problemas que criou. ${ }^{9}$ Compreende-se assim o julgamento sem nuanças de um gassendista como François Bernier, ao fim do século XVII: "Não sei se vos devo dizer que os cartesianos, de tanto especular sobre seu grande princípio - eu penso, logo eu sou - acabaram não apenas acreditando que é bem mais fácil provar que haja substâncias espirituais do que corporais, mas também duvidando a respeito de haver algum corpo na natureza, e sustentando mesmo como provável que não haja nenhum e que tudo seja apenas espírito" (BERNIER, 1835, t. IV, p. 373).

\section{A fecundidade do debate cartesiano no século XVIII}

Será o solipsismo ainda, no século seguinte, tão influente e as refutações que a ele se apresentam, mais conclusivas? Antes de responder a essa questão, duas precisões se impõem. O emprego do termo "solipsismo", que manterei na seqüência, é certamente anacrônico, posto que o conceito não existia antes do século XVIII no sentido com o qual nós o conhecemos hoje. ${ }^{10} \mathrm{Eu}$ entenderei então por solipsismo o que os pensadores das Luzes designavam de maneira unívoca por idealismo ou egoísmo.Além disso, eu não retomarei aqui a questão de saber se houve ou não pensadores que realmente professaram o solipsismo, seja Jean Brunet, Gaspard Languenhert ou ainda outros: o imaterialismo de Berkeley, deformado, bastava para tornar uma tal hipótese plausível. ${ }^{11}$ Mesmo sem ter tido mestres ou líderes de escolas realmente confirmados, o solipsismo não deixa, por isso, de estar intimamente presente em todos os debates metafísicos da época, tanto entre os defensores de um dualismo estrito quanto entre os promotores de um materialismo radical. $O$ que contribuiu, sem dúvida, para um tal sucesso da posição solipsista é, malgrado seu caráter absurdo, sua aparente irrefutabilidade, sublinhada, notadamente, por Thémiseul de Saint-Hyacinte ${ }^{12}$ ou Diderot ${ }^{13}$. Ora, como assinala Louis de Beausobre, o absurdo de um raciocínio não basta para refutá-lo, enquanto ele não for julgado contraditório ou errôneo. Isso vale igualmente, aliás, para o idealismo e o materialismo: "Poderemos mais facilmente demonstrar o erro dos egoístas e dos materialistas? Há, sem dúvida, loucura em imaginar ser o único ser existente, e talvez se humilhe o homem ao dar à matéria a capacidade de pensar; mas não 
posso demonstrar que uma loucura e que uma idéia humilhante sejam erros" (BEAUSOBRE, 1754, p.23).

Posto que a nova metafísica própria ao século XVIII recusa-se a partir da idéia para conhecer o real, proibindo-se, por isso mesmo, o conhecimento do interior absoluto das coisas; posto que ela opera a partir de um ceticismo metodológico a fim de evitar os vícios do dogmatismo racionalista, compreende-se que ela não pode se pensar segundo o modelo de rigor demonstrativo das matemáticas. Não se trata mais de pensar more geometrico, mas de construir empiricamente o saber, e um tal método protege o solipsismo de toda refutação definitiva. Assim, como sublinha, em 1753, Nicolas Béguelin, "os sistemas do acaso, do fatalismo, do idealismo, e mesmo do egoísmo, ainda que pareçam revoltantes àqueles que não os adotam, estão ao abrigo de toda refutação demonstrativa." (BÉGUELIN, 1755, t.XI, p.423). Quais são, então, as críticas que propõem os pensadores das Luzes, a fim de minar a pretensa irrefutabilidade do solipsismo? E poderiam os egoístas a elas responder? Se o fizeram, como veremos, foi através da boca dos próprios homens das Luzes que, sem o pretender, apenas reforçaram a posição dos seus adversários quando se incumbiram de combatê-la.

Deixemos de lado as argumentações ad hominem, numerosas no século das Luzes, onde a ironia é uma arma filosófica como as demais, e que consistem, seja em dizer que é preciso haver dois para convencer um interlocutor e que, portanto, um solipsista deve ao menos supor que é real a existência de seu contraditor, seja em pensar que, no fundo, trata-se de uma doutrina de afetados que pretendem se fazer conhecidos na República das Letras e que seguem o modo de ser comum quando se trata de agir e não mais de meditar. No primeiro caso, é talvez Le Guay de Prémontval o mais espirituoso:

"Nada me parece mais divertido que o sistema de um egoísta dedicado a um mecenas por cujo favor ele batalharia; se, todavia, o livro em si já não fosse tão divertido quanto pôde ser. Provar a outros que é o único! Creio que a dedicatória começaria assim: 'Meu senhor! ... de todas as aparências das quais experimentei a sensação, não há nenhuma pela qual eu teria uma veneração mais profunda do que por vossa excelência.' Em seguida, ele se louvaria infinitamente por essa sensação, pelas obrigações que reconhece ter para com ela, da generosa proteção 
que espera dela. Ele se vangloriaria do mérito e das virtudes que nela admira e debitaria todas as impertinências que se debitam à realidade. Deixemos de lado esse louco..."( PRÉMONTVAL, 1755. pp. 154-155)14

No segundo caso, há igualmente muitos que pensam que o egoísmo é mais um jogo de efeito do que uma verdadeira persuasão da alma. Aliás, quando vem o momento da ação, os céticos se reportam ao costume e aceitam certas evidências, pois se não fosse assim eles não poderiam se decidir no curso de sua existência. É, com efeito, no nível das conseqüências práticas do solipsismo teórico que se percebe a impossibilidade de abraçar uma tal doutrina.

Deixemos igualmente de lado os sofismas, tais como aquele da inclinação fatal, que refuta uma doutrina a partir das conseqüências inadmissíveis que dela se induzem. Encontra-se notadamente um resquício no Padre do Tert re, que insiste nas conseqüências teológicas do solipsismo, mostrando que ele conduz infalivelmente ao ateísmo, pois essa doutrina nega toda a eficácia divina e tira a legitimidade da prova cosmológica da existência de Deus. ${ }^{15}$ Maupertuis e Bonnet evocam, de sua parte, suas conseqüências psicológicas, o primeiro mostrando que "ficar só no universo é uma idéia bem triste" (MAUPERTUIS, 1768, t.II, p.236) e o segundo insistindo na decepção que decorre de uma tal hipótese, pois se o mundo é apenas um fenômeno ele não existe por si mesmo, mas apenas a título de significado apontando para seu criador, que é a significação verdadeira, e não tem, portanto, nenhum interesse em si. De sua parte, Mérian lembra que, ao militar a favor da inexistência da matéria como substância, o solipsismo tem conseqüências metafisicas muito comprometedoras, posto que é fácil concluir, da inexistência do substrato material, à inexistência do substrato espiritual, conduzindo assim à dissolução do eu. A partir daí, "nós não conhecemos, então, absolutamente nada cuja permanência nós pudéssemos garantir e menos ainda a substancialidade. Sujeito e substância, tomados nesse sentido, são termos vazios de sentido, puros seres de razão, isto é, fenômenos, ou seqüências ou amontoados de fenômenos, que nos aprouve nomear abusivamente com esses belos nomes" (MÉRIEN, 1798, p.417). Quanto a Saint-Hyacinthe e Diderot, eles tratam, sobretudo, de suas conseqüências danosas no nível prático. Para Saint-Hyacinte, o egoísmo metafísico pode bem ser pouco compar- 
tilhado pelo comum dos mortais, mas nem por isso ele deixa de favorecer o egoísmo moral, dando-lhe uma justificação metafisica, e de valorizar, por isso mesmo, a decomposição social. Para Diderot, o solipsismo é insustentável no plano prático e sua conseqüência última seria a pura indecisão, o que é impossível. Com efeito, no nível do agir, o cético deve deliberar e aceitar apoiar-se em certas evidências, caso contrário não poderia agir nem justificar sua ação. É, portanto, contraditório adotar uma posição filosófica que não pode se sustentar a partir do momento em que se trata de passar à ação: "o homem uno e verdadeiro não tem, em absoluto, duas filosofias, uma de gabinete e outra de sociedade; ele não estabelece, em absoluto, princípios na especulação que ele será forçado a esquecer na prática" (DIDEROT, 1764, t.XIII, p.614). Acerca desse ponto, Diderot é bem próximo de Hume, sem por isso nele se inspirar, pois, como muito bem mostrou Popkin, o Hume conhecido pelos pensadores das Luzes é o historiador e não o filósofo. ${ }^{16}$ De certa maneira, ao retomar a doutrina pirrônica da adequação ao senso comum no quadro da vida cotidiana, Huet tinha respondido por antecipação a essa crítica de Diderot:

"Quando se trata de conduzir a vida, de desincumbir-se dos deveres, nós cessamos de ser filósofos, de ser contrariantes, duvidosos, incertos; nós nos tornamos tolos, simples, crédulos; nós chamamos as coisas pelos seus nomes, nós retomamos nossos costumes e nosso modo de ser, conformamos nossos modos de agir aos modos de agir dos outros homens, a seus costumes, a suas leis. Eu que há pouco duvidada sobre se eu existia, sobre se havia outros homens, agora bani todos esses pensamentos e, dando como certo que existo e que os outros homens também, eu como, bebo, ando, vou ver meus amigos, cumprimento-os, converso com eles, afirmo, nego, asseguro que isso é verdadeiro e aquilo é falso. Pois, como diz Cicero, 'há uma grande diferença entre a sutileza com a qual se busca a verdade na controvérsia e aquela com a qual ajusta-se o seu raciocínio (discours) à opinião comum"” (HUET, 1723, p.242-243).

\section{Argumentos e contra-argumentos concernentes à existência do mundo exterior}


Uma vez postos de lado esses ataques sofísticos, passemos aos argumentos tidos como realmente capazes de derrubar o adversário cético e demonstrar a existência do mundo exterior. Sublinhemos de saída sua falta de originalidade e sua fraqueza (ponto que terei ocasião de retomar), bem como seu caráter repetitio e anônimo, o que torna possível encontrá-los em autores todavia muito afastados no nível dos princípios filosóficos que invocam. De modo geral, eles podem ser organizados em torno de seis tentativas reputadas como demonstrativas, que põem em cena o consenso universal, o desvio pela mediação divina, a existência de outrem, o caráter necessário da temporalidade, a explicação causal, a distinção entre as qualidades primárias e secundárias e a que há entre o sonho e a vigília.

$\mathrm{O}$ argumento do consenso universal em favor da existência do mundo exterior, igualmente declinado noutras formas, como as do recurso ao bom senso ou ao senso comum, é o mais corrente no século XVIII. Encontramo-lo em autores tão diversos quanto d'Alembert, Para du Phanjas, Ilharat de La Chambre, l'abbé Pluquet, Ancillon ou Béguelin. Sem dúvida é o Padre Buffier quem, no início do século, o formulou nos termos mais adequados. Para este, há ve rdades primeiras, comuns à maioria dos homens, que determinam necessariamente o entendimento e que não se apóiam em nenhum princípio anterior, a primeira das quais estipula a existência de outros seres e de outros homens além de mim. Esta verdade primeira, diz Buffier, "foi tão unive rsalmente aceita pelos homens, em todos os tempos e em todos os países do mundo e por toda a sorte de espíritos, que aqueles que atacassem a certeza evidente da existência dos corpos não seriam um a cada mil, nem mesmo a cada cem mil." (BUFFIER, 1732, p. 572, col. B). Tal verdade permite explicar simplesmente o fato de que a grande maioria dos homens compartilha da idéia de que o mundo exterior é real, enquanto que seu caráter ilusório só aparece como tal a uma ínfima minoria dentre eles. O solipsismo não pode, portanto, ser uma verdade primeira; bem ao contrário, trata-se de uma proposição filosófica alcançada através de um raciocínio complexo. Se todos fossem de boa fé, como reclamam por exemplo Bonnet ou d'Holbach, ${ }^{17}$ ou se fiassem no bom senso ou no senso comum, como o exigem d'Alembert e, mais tarde, Béguelin ou Ancillon, ${ }^{18}$ a questão da existência dos corpos exteriores não deveria sequer ser posta. 
A isso, os céticos têm o hábito de responder que sua própria existência é um flagrante desmentido de todo o consenso universal sobre a questão, que o acordo de uma maioria de homens sobre um postulado não é uma garantia da exatidão desse postulado (afinal, os homens acreditaram por muito tempo que era o Sol que efetuava uma revolução em torno da Terra) e que o senso comum devia se ater unicamente à existência do senso íntimo que nos faz conhecer o que se passa em nós, mas não pode nos instruir acerca do que é exterior a nós. Com efeito, o solipsismo parece mesmo mais lógico e sua formulação silogística, proposta por Lelarge de Lignac, parece inapelável:"dos corpos, nós conhecemos apenas as qualidades sensíveis; ora, as qualidades sensíveis não podem estar nos corpos, sendo afecções de uma substância espiritual; portanto, nós não conhecemos nenhum corpo" (LIGNAC, 1753, pp. 306-307). Esta superioridade do idealismo se explica pelo fato de que as outras teorias epistemológicas - a saber, o dualismo e o monismo materialista - não conseguem explicar a relação que une a alma, considerada como um corpo simples, e os objetos pretensamente compostos que a afetariam, bem como a relação entre as idéias espirituais e os corpos materiais que elas supostamente representam. Ora, nos dois casos o monismo espiritualista parece resolver de modo pertinente os problemas, como sublinhou com justeza d'Alembert no artigo "Corpo" da Encyclopédie: "Nossa alma sendo espiritual e as idéias que formamos dos objetos nada tendo de comum ou análogo a esses mesmos objetos, segue-se que essas idéias não podem ser produzidas por esses objetos. O objeto de uma idéia só pode ser uma outra idéia e não teria como ser uma coisa material. Assim, o objeto da idéia que temos dos corpos é a própria idéia que Deus tem dos corpos, idéia que em nada se assemelha aos corpos e não teria como a eles se assemelhar" (D'ALEMBERT, 1754, t. IV, p. 262). Forçoso é constatar que o solipsismo, postulando uma conformidade ontológica entre as idéias e os objetos, entendidos como entidades espirituais, parece resolver adequadamente as questões da semelhança entre idéias e objetos e da ação recíproca entre a alma e o corpo.

O segundo argumento, não mais original, é aquele que consiste em fazer intervir o conceito cartesiano de Deus veraz. Se ele é requerido unicamente pelos crentes, pode-se dizer que, tal como o consentimento universal, ele será retomado ao longo de todo o século XVIII. Encontra- 
se uma primeira formulação explícita sob a pena de Jean-Pierre de Crousaz, na sua Logique de 1712, que será retomada de modo quase idêntico ao longo de todo o século. Nada de muito estranho nisso, posto que, como o confirma Turgot ${ }^{19}$, trata-se aí de uma resposta convencional que os jesuítas apresentaram como probatória a várias gerações de colegiais. ${ }^{20}$ Apenas duas utilizações diferentes do argumento merecem ser notadas, pois têm o mérito de redobrar a suposta culpabilidade divina na ausência de um mundo exterior real. A primeira é formulada por Bouiller e retomada por Turgot: consiste em dizer que Deus seria, nesse caso, não apenas enganador, mas igualmente cruel, e que o sofrimento não teria nenhuma razão de ser. Com efeito, por que nos fazer sofrer se a causa desse sofrimento é puramente ilusória? Inversamente, a existência de um Deus veraz e bom permite justificar o mal e o sofrimento no seio de um universo criado em vista do máximo de satisfação possível. ${ }^{21} \mathrm{~A}$ segunda, esboçada em primeiro lugar por d'Alembert e pelo abade Pluquet, é explicitada pelo abade Lecren; ela evoca igualmente o fato de que Deus seria duplamente falível e, mais particularmente, duplamente enganador. É fácil compreender: não apenas Deus nos lograria ao permitir que aquilo que nos afeta não exista, mas ele nos enganaria igualmente ao fazer com que nossa inclinação natural; nosso instinto, ao atribuir nossas percepções a objetos exteriores a nós; inclinação essa à qual não podemos resistir (como não tremer quando ruge o trovão ou não sorrir quando se percebe algo agradável?), seja falsa. Assim, "eu não posso, portanto, me incriminar por haver a ilusão, e como seria preciso atribuí-la ao Ser supremo, que pela sua natureza é incapaz disso, eu me asseguro de que ele não ocorre e não pode ocorrer" (LECREN, 1763, p.150). Mas outros argumentos teológicos foram propostos durante todo o século que, embora certamente menos em voga que o do Deus veraz, tiveram uma importância igualmente não desprezível. Citemos, dentre outros, o fato de que a inexistência do mundo exterior torna Deus imediatamente inculpável do pecado e que essa inexistência é não apenas contrária ao texto revelado mas seriamente danosa à doutrina cristã da incarnação.

Poderia a concepção do Deus veraz apanhar os solipsistas de surpresa? D'Alembert pensa que não, simplesmente porque a concepção de um Deus veraz, para os pensadores do século XVIII, que geralmente conservam apenas a prova a contingentia mundi da existência de Deus, é circular 


\section{4}

e inverte a ordem das prioridades: ela consiste em dizer que a existência dos corpos depende da existência de Deus enquanto ela é a sua condição. ${ }^{22}$ Além disso, p o rque a doutrina da veracidade divina supõe que Deus nos deva algo, o que, seguindo neste ponto Boureau-Deslandes, é bem presunçoso de nossa parte: "ainda que nada existisse na natureza, esse eu poderia sofrer as mesmas modificações, poderia sentir dor ou alegria, e nisso Deus não nos faria nenhum ultraje ou injúria, posto que não me deve nada, e, no fundo, as percepções que tenho dos corpos não são relativas aos seres reais, podendo muito bem estar de acordo com seres que eu acreditasse existir sem que existissem de fato" (BOUREAU-DESLANDES, 1742, t. II, pp. 317-318).

O terceiro argumento, que consiste em refutar o solipsismo demonstrando a existência de outra coisa além de si próprio, a partir da existência do eu, graças a uma infalibilidade do cogito raramente contestada, ${ }^{23}$ não se põe em questão. Esse argumento é mais raro e se declina sob duas formas diferentes: aquela que consiste em provar a existência de outro e aquele que insiste na noção de alteridade. No primeiro caso, deve-se mencionar o abade Joannet. Este propõe uma concepção original que supostamente refutaria o solipsismo e que parte da idéia da lei moral inscrita em cada um de nós. Essa lei moral nos obriga em relação a outrem e nos envergonha quando nos recusamos a nos conformar a ela. Ora, a existência desse sentimento moral não teria nenhum sentido se o outro não existisse realmente ${ }^{24}$ (estamos novamente bem próximos do argumento do Deus veraz) e pode-se legitimamente concluir que a lei moral é a prova de que o mundo não se reduz a uma única consciência. No segundo caso, que concerne à alteridade, podemos nomear diversos jesuítas, dentre eles o padres Tournemine e Buffier. Para o primeiro, a alteridade é irredutível a toda consciência humana. A presença em nós de idéias que não são de nós mesmos implica a existência de um outro ser do que nós, que é sua causa, ou de uma ordem natural exterior, argumentação esta retomada quase palavra por palavra pelo padre do Tertre. ${ }^{25}$ Se assim não fosse, seria preciso encarar o solipsismo como causa sui, possuindo uma essência necessária e imutável, o que não é possível, uma vez que seu espírito é modificado sem cessar por idéias que não provêm de seu próprio interior, o que indica bem sua contingência e sua dependência. ${ }^{26} \mathrm{O}$ abade Gérard acrescentará, no final do século, que tal 
dependência pode facilmente se compreender a partir do fato de que não podemos criar o que não conhecemos, tal como o fruto exótico desconhecido que apenas se torna familiar a nós se vamos ao lugar onde ele dá e que, portando, existia sem que tivéssemos consciência dele. ${ }^{27}$ Quanto ao segundo, o padre Buffier, um raciocínio lógico pode bastar para explicitar a noção de alteridade e a fazê-la adquirir uma dimensão real. Partamos do fato de que o solipsista tem essa noção de algo diverso dele. Como a pode explicar? Se é inata, é portanto a natureza que lhe proviu (ela é verdadeira); se é adquirida, existe outra coisa além de nós.

Desta bateria de argumentos, guardemos apenas o último. É porque o egoísta teria em seu espírito a noção do outro que a alteridade seria necessária, nos diz Buffier. Ora, o solipsista pode muito bem ter forjado essa noção do outro por analogia, examinando suas idéias e comparando suas diferenças. Como uma idéia é diferente de outra, sua alteridade, assim, é efetiva e a noção de outro pode se explicar, então, num espírito solipsista.

Quarto argumento, concernente ao caráter necessário da temporalidade. Ainda aí é preciso recorrer ao padre Tournemine. Para este, ou bem o espírito do solipsista foi criado (e nesse caso existe algo além dele), ou bem deve ser considerado como eterno, mas nesse caso nosso solipsista nem sempre pensou e se tornou ativo apenas a partir de um certo momento, o que consiste em fazer absurdamente a duração intervir na eternidade. Além de Tournemine, François Quesnay aporta outro argumento interessante a partir de considerações temporais. Para se opor ao solipsismo, Quesnay elogia os méritos da memória como liame estruturador entre aquilo de que nós nos lembramos, que foi presente no momento em que nós o sentimos, e o que nós percebemos. Rever um mesmo lugar pressupõe ao mesmo tempo a persistência do eu e da coisa percebida no tempo, o que implica uma persistência no ser independente dos dois lados: "a evidência com a qual nossas sensações nos indicam nosso ser sensitivo e a evidência com a qual as mesmas sensações nos indicam o corpo é a mesma; ela se limita, de uma parte e de outra, à simples indicação e não tem outro princípio além de nossas sensações, nem outra certeza do que aquela de nossas próprias sensações, mas essa certeza nos comanda e nos submete soberanamente" (QUESNAY, 1756, p.153).

$\mathrm{O}$ que se pode responder de um ponto de vista solipsista? Por mais estranho que possa parecer, é um jesuíta, o padre Buffier, que aqui se faz 
adversário de Tournemine. Para ser eficaz, a demonstração de Tournemine deve admitir como pressuposto que a eternidade supõe uma forma de perfeição e, portanto, uma consciência permanente. Ora, poderia ocorrer que sejamos eternos sem saber, pois poderíamos ter existido antes mesmo de ter a lembrança disso. Posto que a memória é uma faculdade falível e que o passado não tem sentido a não ser no presente, poderia ocorrer que nossas lembranças abarquem apenas uma parte de nossa existência, não sua totalidade. O solipsista pode legitimamente ter esquecido que ele é eterno e recusar-se a crer naqueles que dizem que seu espírito foi produzido, pois ter sido produzido é uma coisa passada e não atual, e tudo o que é do passado está sujeito a caução. ${ }^{28}$ Mas nossa imperfeição, nossos erros e nosso sofrimento não testemunham de nosso estatuto de ser finito e não-eterno? Isso é ainda confundir perfeição e eternidade. Em que um ser eterno não poderia ser imperfeito? Nós poderíamos ser assim por uma necessidade de natureza e, como confessa o abade Pluquet, toda boa metafísica supõe um ser necessário. ${ }^{29}$

O quinto argumento, ainda bem usual e já empregado por Locke, remete ao princípio de causalidade, a propósito do qual Turgot disse, sem dúvida, o essencial, procedendo de modo silogístico: não há efeito sem causa; ora, as sensações são efeitos; portanto, têm uma causa. Mignard propõe uma versão similar dele: existir é agir; ora, há coisas que agem sem nós; portanto, existem coisas independentes de nós. ${ }^{30}$ Para dizê-lo ainda mais brevemente, desta vez acompanhando Selles, se há o aparecer é porque existe o ser. ${ }^{31}$ Como o caso do sonho pode criar alguma confusão, acrescenta-se pelo bem da causa a idéia de repetição temporal como garantia de uma persistência real das coisas. Quesnay, como vimos, havia vislumbrado isso, mas Maupertuis irá mais longe combinando-a com a causalidade para dela fazer a única prova demonstrativa da existência do mundo exterior. $\mathrm{O}$ que funda no ser as coisas corporais é sua permanência temporal que a repetição perceptiva permite apreender. Se voltamos dive rsas vezes a uma mesma cidade e aí encontramos uma praça sempre idêntica, ela é verdadeiramente independente de nós, não tem necessidade de ser percebida por nós para que digamos que é realmente existente e podemos prever que, em nossa próxima passagem pela cidade, nós a reveremos. ${ }^{32}$

$\mathrm{O}$ recurso à causalidade prova verdadeiramente a existência de corpos exteriores? Pode-se duvidar; pois, afinal de contas, o que demonstra de 
fato? Ele torna explícita uma única coisa, a saber, que nós somos afetados. Mas o ponto é: o que nos afeta? Deus, a natureza, os objetos ou o substrato material? A questão permanece em suspenso.

Sexto argumento, concernente aos sentidos e também à famosa distinção entre qualidades primárias e secundárias. No que tange aos sentidos, os céticos haviam insistido repetidamente nas ilusões perceptivas, para recusar sua consideração como critérios epistemicamente válidos. Para os filósofos das Luzes, essa crítica é excessiva e pode-se reconhecer a um acordo sensorial uma certa validade epistemológica. Com efeito, se combinamos duas percepções, o tato e a visão, por exemplo, podemos resolver certas dificuldades céticas e chegar a ter uma concepção de mundo relativamente exata e despida de ilusão sensorial. Mas, além disso, os sentidos avançam, paradoxalmente, ao ponto de nos informar adequadamente acerca da existência de um mundo exterior independente de nós. A concordância entre os sentidos entre si é a garantia da existência do mundo exterior. A conjunção entre a visão e o tato, por exemplo, faz-nos compreender que os objetos vistos e tocados ao mesmo tempo são causas comuns de nossas sensações e delas são, ao mesmo tempo, dependentes e independentes. ${ }^{33}$ A isso se pode acrescentar a idéia da dupla percepção individual: duas pessoas vendo um mesmo objeto testemunham em favor de um referente externo independente delas. Como escreve Bouiller: "que um francês e um japonês comuniquem um a outro suas percepções sensíveis, ve reis pela exata correspondência dessas idéias que são representações de um mesmo todo. Sem uma tal correspondência, seria mesmo impossível a esses dois homens se encontrarem para comunicar algo." (BOUILLER, 1737, p.140).

Além do mais, os sentidos testemunham em favor da existência do mundo exterior na nossa apercepção da alteridade de uma forma dupla, na percepção dos obstáculos e da resistência. A idéia da percepção dos obstáculos, evocada por Condillac na segunda edição do Tratado das Sensações, permite reverter o subjetivismo (na medida em que os obstáculos garantem a presença dos objetos independentemente de nossa percepção) e explicar a existência de duas coisas extensas mutuamente exclusivas e, portanto, de dar um certo crédito ao juízo natural de exterioridade que nos é próprio. Quanto à noção de resistência, ela é o grande 
achado de Destutt de Tracy e lhe permite partir de uma posição solipsista para superá-la adiante. Para Tracy, é possível libertar-se do solipsismo e mostrar que o sensualismo não nos condena ao egoísmo, concedendo aos idealistas sua tese central, a saber, a do primado do sentimento íntimo sobre todo outro conhecimento. Mas conhecer-se como sujeito pensante não implica, nessa medida, uma limitação original desse saber apenas às percepções subjetivas do eu: além do sentir, o sujeito possui o querer, de tal modo que ele tem naturalmente tendência a ir além de si mesmo para o exterior e se confrontar com o mundo que o cerca, dive rso dele. "Resistir, portanto, é existir; é uma qualidade bem real, portanto, a de resistir a mim. O ser que a possui é, portanto, bem verdadeiramente um ser e um ser diverso de mim" (DE TRACY, 1992, p.217). Todavia, esse existente que resiste a mim é sempre existente a título de ser percebido e o fato de que ele se opõe à minha vontade o torna, apesar de tudo, ainda relativo a essa mesma vontade. Ora, supondo-se que esse objeto não seja ilusório, a resistência que ele oferece nada diz de sua essência, que bem poderia ser espiritual. Mantendo ativa a distinção entre qualidades primárias e secundárias, o problema da saída do eu subsiste integralmente, tal como o compreenderam os pensadores das Luzes.

É isso, sem dúvida, que explica a preocupação expressa por alguns de se libertar disso e de dar a entender que o interior absoluto das coisas pode ser alcançado pela mediação dos sentidos. Voltaire, por exemplo, dá a entender que o tato é capaz de nos dar uma idéia verdadeira da matéria, fazendo-nos concebê-la como impenetrável e independente de nós. ${ }^{34}$ Ele chega mesmo a recusar, em termos bem claros, a distinção entre qualidades primárias e secundárias no que concerne à extensão, que é ontologicamente diferente das outras percepções sensíveis. A extensão não é apenas uma qualidade secundária, como o são o som e a cor, que só existem ao ser percebidos, mas uma propriedade intrínseca dos objetos circundantes. Essa rejeição taxativa de uma das teorias modernas mais em voga será retomada notadamente por Gabriel Gauchat e Bergier, que são adversários de Voltaire, todavia, quanto a vários pontos. Ambos compreenderam precisamente que essa distinção só pode ser dispensada em proveito das qualidades segundas e favorecer o solipsismo, e que é preciso reconhecer que certas qualidades sensíveis, as que concernem ao tato e à vista, são ao mesmo tempo subjetivas e objetivas. ${ }^{35}$ 
Quanto à questão do peso relativo a conferir aos sentidos no processo epistemológico, o diagnóstico solipsista tem, ele também, bons argumentos a oferecer. Se o argumento dos sentidos enganadores é raramente mencionado, aquele, inversamente, que se funda na distinção entre qualidades primárias e secundárias é onipresente nos debates epistemológicos do século XVIII. Pode-se ir além das nossas afecções subjetivas? É a extensão uma qualidade diferente das outras? Podem certos sentidos conduzir a uma forma de objetividade? É legítima a superioridade do tato e da visão? A todas essas questões, a resposta oferecida é negativa. Enquanto Voltaire entendia que a extensão não é redutível a uma sensação, Bergier lhe responde que não se pode pretender refutar o puro subjetivismo desse modo. Os exemplos oferecidos porVoltairepara distinguir a extensão das outras qualidades percebidas - a lenha apagada que não mais aquece, o ar imóvel que não produz som, a rosa seca que não tem cheiro - podem igualmente bem ser contrapostos por outros exemplos igualmente eloqüentes: "igualmente, que essa lenha continue a queimar, sua extensão diminuir e ela enfim desaparecerá; que esse bastão de seis pés seja partido ao meio, vejo apenas dois pedaços de três pés cada um; eis, portanto, na extensão a mesma alteração que nas cores, nos sons, nos odores; onde está a diferença?” (BERGIER, 1855, p.721). Onde ela está, com efeito, se a extensão deve, apesar de tudo, ser percebida para que digamos que ela existe? O questionamento de Bergier tem igualmente como conseqüência o fato de minar a prerrogativa dos dois sentidos pretensamente mais objetivos que os demais, a saber, o tato e a visão. No fundo, como bem vê Mérian, o fato é que a visão e o tato são dois sentidos que tendem a objetivar as coisas, mas têm uma superioridade apenas imaginária sobre os outros sentidos, e os objetos que eles permitem apreender não têm mais realidade do que os do gosto, da audição e do olfato. ${ }^{36}$ Quer-se uma prova? Basta pensar na estrela que ainda percebemos pela visão embora ela já tenha deixado de existir há milhões de anos. A visão não é, portanto, como também não o é o tato, um sentido capaz de garantir a existência objetiva e externa dos objetos percebidos. E se, apesar de tudo, concebíamos como possível a existência de um interior absoluto das coisas, ninguém seria apto a dizer qual é sua essência e se ela deve ser compreendida em termos material ou espiritual. Eis por que afirmar que a matéria é um "não sei quê", posição amplamente privile- 
giada pelos pensadores das Luzes, não pode senão desembocar numa tendência monista, idealista ou materialista. Ora, se a matéria é como se define habitualmente, isto é, uma substância extensa e inerte, o solipsismo é absolutamente irrefutável, pois como poderia ela ser causa de nossas sensações, ativa, portanto, se a inércia é um de seus atributos?

Último argumento, concernente à semelhança entre o sonho e a vigília. É conhecida a força da utilização dessa semelhança. O interesse do sonho reside em que ele prova inapelavelmente que a alma pode ser afetada sem, com isso, perceber objetos exteriores. A sensibilidade, inoperante na produção do sonho, poderia sê-lo, então, igualmente na vigília. Ademais, não é isso mais simples - posto que isso é possível no caso do sonho, onde temos uma idéia dos corpos sem por isso percebê-los - de permanecer num puro subjetivismo? Como escreve Pichon, "Uma vez que Deus é a sabedoria soberana, segue-se que ele age sempre pelas vias mais simples. Portanto, ele não criou os corpos, posto que sem essa criação o espírito do homem pode receber uma sucessão de imagens corporais e experimentar todas as suas impressões." (PICHON, 1763, p.5). Para responder a essa eventualidade, tende-se a recorrer à distinção explícita que existe entre as idéias do sonho e da vigília. Além da oposição clássica entre percepções do sonho - obscuras, confusas, amorfas e sem coerência - e as que temos acordados - claras, distintas, vivas e ligadas entre si - Selle aporta um argumento original que consiste em tornar necessária a existência do mundo exterior a fim de permitir a distinção entre sonho e vigília. Se as coisas reais só existissem na nossa imaginação, como as coisas possíveis, então não se poderia oferecer nenhuma razão da diferença existente entre o possível e o necessário, o sonho e a realidade. ${ }^{37}$

$\mathrm{Na}$ questão da distinção entre sonho e vigília os solipsistas estão em seu território, ou, antes, aqueles que professam um idealismo absoluto. Basta aqui empregar o método, apreciado pelos Acadêmicos, do sorites. onde se situa exatamente a diferença de vivacidade entre o sonho e a vigília, entre a nitidez do sonho e do despertar?38 Não temos, durante a vigília, como observam Form ey e Beausobre, 39 idéias que advêm sem nenhuma ligação com aquilo em que pensávamos? Não é também possível conceber, durante o sono, sonhos perfeitamente encadeados que permitem duvidar realmente, quando despertamos, de sua inexistência? E 
por que seria a vigília que precederia o sonho, este último sendo apenas uma reprodução imperfeita e menos ordenada? Quem nos disse que as sensações caóticas experimentadas durante o sonho não constituem um estado primeiro e que as sensações ordenadas da vigília dependem dele? O autor anônimo do artigo da Enciclopédia consagrado ao sonambulismo retoma esse questionamento por sua conta e se ri das explicações realistas demasiado desembaraçadas de seus contemporâneos:

As maiores provas que a filosofia oferece da existência dos corpos são fundadas nas impressões que eles nos causam. Essas provas perdem necessariamente muito de sua força se sentimos os mesmos efeitos sem que esses corpos realmente ajam. É precisamente o caso do sonâmbulo, que gela e se arrepia sem ter sido exposto à ação da água gelada, mas simplesmente por tê-lo imaginado. Parece, assim, que as impressões ideais fazem por vezes tanto efeito sobre os corpos quanto as reais e que não há nenhum signo seguro para distingui-las. ${ }^{40}$

Ora, o outro problema que se põe aos filósofos demasiado solícitos na distinção entre as percepções vivas da vigília e as percepções confusas do sonho concerne à relação entre sensações presentes e sensações passadas, isto é, as que são conservadas na memória. Se se quiser salvar a diferença real entre a vigília e o sonho pela clareza e distinção, mina-se automaticamente a credibilidade da memória, que também se define por lembranças obscuras e confusas. D eve-se concluir que elas são ilusórias, como alguns são levados a pensar?

Essas diferentes objeções, pareçam elas fracas ou válidas no plano estritamente lógico, minam a credibilidade das refutações veiculadas ao longo de todo o século à doutrina do egoísmo e testemunham da possibilidade de sempre levar além o questionamento sem nunca se satisfazer com esta ou aquela evidência. Ora, o mais espantoso é constatar que são os próprios pensadores das Luzes que se dedicarão a afiar as armas que, na seqüência, julgarão invencíveis, e que, ao confundir duas problemáticas um ceticismo epistemológico (a essência das coisas é incognoscível) e um ceticismo ontológico (a existência dos corpos não pode ser provada) eles não terão levado grande vantagem. Ao final, para a grande maioria deles, um acordo parece poder ser alcançado: o como o idealismo absoluto, mesmo irrefutável, é demasiado absurdo, é preciso dele se afastar e 
propor uma outra doutrina mais conforme ao senso comum. É aí novamente que as opiniões divergem: para alguns, em grande parte homens das Igreja, um retorno ao dualismo do início do século permanece admissível e é assim que Boullier, Aubry ou Schwab reabilitam o inatismo cartesiano; Wolff e Béguelin, a harmonia pré-estabelecida leibniziana; o abade Boncerf, o ocasionalismo malebranchista. Para outros, o monismo materialista é a única saída que resta para resolver a questão. É o que contesta, com justiça, Delisle de Sales na sua Filosofia da Natureza: "como tudo o que se vê é matéria, supõe-se que a extensão é a essência de tudo o que existe; esse raciocínio convém à preguiça mental humana, e é adotado, não por ser justo, mas porque poupa de pesquisas." (DE SALES, D. 1789, p.297). Para os mais prudentes, e talvez mais exigentes, o materialismo é aceito a título de hipótese mais simples ${ }^{41}$ e mais provável.

A palavra final das Luzes é exatamente a da probabilidade, já evocada no meio do século por d'Alembert e retomada em conjunto por Brissot de Warville, Condorcet e Jean-Pierre de La Métherie, que chegaria a propor, nos seus Princípios da Filosofia Natural, de 1787, um quadro das certezas no interior do qual a existência dos corpos externos obterá o grau máximo na ordem das probabilidades, sem com isso aceder à certeza plena e inteira. Mas o que mais se pode esperar de uma metafísica que desejava não transpor indevidamente os limites que a natureza havia prescrito à razão humana? $O$ crepúsculo das Luzes culmina numa constatação epistemológica pouco reluzente: o conhecimento da essência das coisas está fora do alcance do entendimento humano, cujas fronteiras naturais assinalam limites estritos a seu poder de conhecer. Ao tomar o sujeito de todo conhecimento como objeto de ciência, a filosofia do século XVIII pôde obter um certo número de conquistas incontestáveis graças a um método epistemológico novo (o empirismo), caracterizado por uma modéstia real diante dos fatos, recusando antecipadamente ceticismo e dogmatismo, ao menos em suas pretensões apodíticas.

\footnotetext{
${ }^{1}$ Acerca de tudo isso, ver o artigo muito instrutivo de Charles McCracken, Knowledge of the Existence of Body, in D. Garber and M.Ayers (ed.), The Cambridge History of Seventeenth-Century Philosophy, Cambridge University Press, Cambridge 1998, t. I, pp. 624-648 bem como as obras indispensáveis de Richard Popkin, Histoire du scepticisme d'Érasme à Spinoza, Presses
} 
Universitaires de France, Paris 1995 e de Gianni Paganini, Scepsi Moderna. Interpretazioni dello scetticismo da Charron a Hume, Busento, Cosenza 1991. Para um exame recente e exaustivo do ceticismo moderno, ver a coletânea diriga pelo mesmo Paganini, The Return of Scepticism from Hobbes and Descartes to Bayle, Kluwer, Dordrecht 2003

${ }^{2} \mathrm{O}$ artigo 70 da primeira parte dos Princípios fornece a demonstração disso a propósito das cores: "É portanto evidente, quando dizemos a alguém que nós percebemos cores nos objetos, que isso equivale a dizer que nós percebemos nesses objetos algo cuja natureza ignoramos mas que causa em nós, contudo, uma certa sensação muito clara e manifesta que nós denominamos sensação das cores” (DESCARTES, 1964-1974, vol. IX, p. 57).

${ }^{3}$ Lanion, Méditations sur la métaphys sique,VIe Méditation ; citado por François Pillon, L'idéalisme de Lanion, in «L'Année philosophique» (1895), p. 126. Encontra-se uma formulação idêntica em Locke, An Examination of P. Malebranche's Opinion of Seeing all Things in God, $\$ 20$.

${ }^{4}$ Ver sobre isso o estudo de Maria Teresa Marcialis, Sceptical Readings of Cartesian Evidence in 17th and 18th Century Italy, in Gianni Paganini, The Return of Scepticism, cit., pp. 231-245.

${ }^{5}$ Sobre as críticas ao cartesianismo aportadas por Foucher, cf. R. Watson and M. Grene, Malebranche's First and Last Critics: Simon Foucher and Dortous de Mairan, Southern Illinois University Press, Carbondale and Edwardsville 1995.

${ }^{6}$ Sobre esta questão ler-se-ão com proveito as análises de Gianni Paganini, Analisi della fede e critica della ragione nella filosofia di Pierre Bayle, La Nuova Italia, Firenze 1980, e de Gianluca Mori, Bayle philosophe, Honoré Champion, Paris 1999.

7 Cf. o nosso L'immatérialisme dans les manuscrits clandestins du siècle des Lumières, «Dialogue», 3 (2000), pp. 491-511.

${ }^{8}$ Para um estudo mais aprofundado da presença do solipsismo nas revistas da época, ver nosso "Deux cas de réception déformée au siècle des Lumières: Spinoza et Berkeley", in Actes du XIVe Congrès Interaméricain de philosophie, Puebla, 2000, pp. 598-611.

${ }^{9}$ Ver, a propósito disso, as análises esclarecedoras de Richard Watson, The Downfall of Cartesianism 1673-1712. A Study of Epistemological Issues in Late 17th Century Cartesianism, Martinus Nijhoff, The Hague 1966 e The Breakdown of Cartesian Metaphy sics, Hackett, Indianapolis/Cambridge 1998 (second edition).

10 Algumas precisões sobre o termo "solipsismo". Se o seu emprego parece anacrônico, é preciso levar em conta que o seu equivalente latino data do século XVII e que o termo será igualmente empregado no século XVIII, ainda que as ocorrências sejam raras e o sentido, diferente. Assim, pode-se notar que Melchior Inchofer publica uma Monarchia Solipsorum em Veneza, em 1645, que em seguida é traduzida em francês por Restaut com o título de $L a$ Monardie des solipses (Amsterdam, 1721). O termo designa os habitantes de uma ilha imaginária que vivem sob a condução providencial de diversos deuses, o que constitui um ataque mal-disfrçado à política maleável dos jesuítas da época, que os levava a sempre buscar a proteção dos poderosos. É Kant, ao que parece, quem primeiramente, na Crítica da Razão Prática, utiliza solipsismus como terminus technicus que substitui o alemão Selbstsucht.

${ }^{11}$ Ver, sobre isso, nosso Berkeley dans la pensée des Lumières. Immatérialisme et scepticisme au XVIIIe siècle,Vrin, Paris 2003.

doispontos, Curitiba, São Carlos, vol. 4, n. 2, p.13-38, outubro, 2007 
12 Saint-Hyacinthe, Recherches philosophiques sur la nécessité de s'assurer par soi-même de la vérité, sur la certitude de nos connaissances et sur la nature des êtres, Alex. Johnson, Rotterdam et La Haye 1743, pp. 94-95: "É preciso entretanto convir que, por mais extravagante que essa opinião possa a princípio parecer (...), quando a examinamos pelo raciocínio é uma das mais dificeis a refutar, se é que o podemos...".

13 É conhecida a posição de Diderot a respeito de Berkeley na Carta sobre os cegos, segundo quem o absurdo sistema do imaterialismo, "para a vergonha do espírito humano e da filosofia, é o mais dificil a combater" (in Euvres complètes, Hermann, Paris 1975, t. IV, p. 44).

${ }^{14}$ A idéia se apresentava já em Andrew Baxter, An Enquiry into the Nature of the Human Soul, A. Millar, Londres 1745, p. 249. Encontram-se gracejos da mesma ordem no padre Buffier, em Cartaud de la Villate,Voltaire, Diderot, d'Alembert, d'Holbach, Euler, Béguelin etc.

15 Rodolphe du Tertre, Entretiens sur la religion, où l'on établit les fondements de la religion révélée contre les athées et les déistes, Clousier, David, Durand et Damonneville, Paris 1743.

16 Richard Popkin, Scepticism in the Enlightenment, «Studies on Voltaire and the Eighteenth Century», 26 (1963) e Scepticism and Anti-Scepticism on the Latter Part of the 18th Century, in P. Fritz and R. Morton (eds.), Woman in the 18th Century and Other Essays, Samuel Stevens Hakkert, Toronto and Sarasota 1976.

17 Bonnet, Essai de psychologie, in Euvres d'histoire naturelle et de philosophie, Fauche, Neuchâtel 1783, t. XVII, pp. 89-90. D'Holbach, Essai sur les préjugés, in Euvres philosophiques complètes, Alive, Paris 1999, t. II, p. 111.

18 D’Alembert, Expérimental, in Encyclopédie, Briasson, Paris 1756, t.VI, p. 300; Béguelin, Essai sur les justes bornes qu'on doit assigner aux spéculations métaphysiques, dans Nouveaux Mémoires de l'Académie Royale des Sciences et Belles Lettres de Berlin, Berlin 1780, p. 396; Ancillon, Mémoire sur les fondements de la métaphysique [1799], nas Mémoires de l'Académie Royale des Sciences et Belles Lettres de Berlin, George Decker, Berlin 1803, p. 143.

${ }^{19}$ Ver suas Remarques critiques sur les Réflexions philosophiques de Maupertuis sur l'origine des langues et la signification des mots [1750], in G. Schelle (éd.), Euvres de Turgot,Alcan, Paris 1913, t. I, p. 174.

${ }^{20}$ Mencionemos, dentre muitos outros, o recurso ao Deus veraz cartesiano proposto por de Saintignon, Traité abrégé de physique, à l'usage des collèges, Durand, Paris 1763 ; Lecren, Principes de certitude, ou Essai sur la logique, Dessain, Paris 1763 ; Para du Phanjas, Éléments de métaphysique sacrée et profane, ou théorie des êtres insensibles, Jombert, Paris 1767 ; Gerdil, Principes métaphysiques de la morale chrétienne [1770], in Nouveaux opuscules du cardinal Gerdil, Rome 1812; Joannet, De la connaissance de l'homme, dans son être et dans ses rapports, Lacombe, Paris 1775.

21 Boullier, Essai philosophique sur l'âme des bêtes, François Changuion, Amsterdam 1737, pp. 138145 ; Turgot, Deuxième lettre à l'abbé de ... sur le système de Berkeley, in Euvres de Turgot, cit., t. I, p. 190.

22 D'Alembert, Éléments de philosophie, chap.VI, in Euvres complètes de d'Alembert, Belin, Paris 1821, t. I, p. 181.

23 O tomo I de La religion vengée (Chaubert, Paris 1757) evoca bem as dúvidas levantadas contra o cogito por Huet no século precendente, e notadamente a acusação de circularidade, mas o faz para melhor delas se afastar.

doispontos, Curitiba, São Carlos, vol. 4, n. 2, p.13-38, outubro, 2007 
${ }^{24}$ Abbé Joannet, Les bêtes mieux connues. Entretiens, Costard, Paris 1770, t. I, pp. 148-149.

25 Rodolphe du Tertre, Entretiens sur la religion, où l'on établit les fondements de la religion révélée contre les athées et les déistes, Clousier, David, Durand et Damonneville, Paris 1743. A mesma idéia está em Ancillon, no seu Dialogue entre Berkeley et Hume [1796], in Mémoires de l'Académie Royale des Sciences et des Belles-Lettres, Decker, Berlin 1799.

26 Tournemine, Réflexions sur l'athéisme, in Mémoires de Trévoux, janeiro de 1719, pp. 49-54.

27 Gérard, Essai sur les vrais principes, relativenent à nos connaissances les plus importantes, Blaise, Paris 1826 , t. I, p. 34 .

28 Buffier, Traité des premières vérités et de la source de nos jugements [1724], retomado no Cours de science sur des principes nouveaux et simples pour former le langage, l'esprit et le ccur, dans l'usage ordinaire de la vie, Cavelier et Giffart, Paris 1732, pp. 561-562.

29 Pluquet, Examen du fatalisme, ou exposition et réfutation des différents systèmes de fatalisme qui ont partagé les philosophes sur l'origine du monde, sur la nature de l'âme, et sur le principe des actions humaines, Didot et Barrois, Paris 1757, t. II, pp. 222-224.

30 Mingard, Existence, in Encyclopédie, Yverdon, 1775, t. XVIII, p. 31.Ver igualmente o artigo Spiritualité do mesmo Mingard, ainda na Encyclopédie de Yverdon.

31 Esta pretensa demonstração se acha em Selle, De la réalité et de l'idéalité des objets de nos connaissances [1786-1787], in Mémoires de l'Académie Royale des Sciences et Belles-Lettres, Decker, Berlin 1792, p. 605.

32 Maupertuis, Réflexions sur l'origine des langues, et sur la signification des mots, in Euvres de Maupertuis, cit., t. I, p. 279: "Eu experimento uma percepção composta da repetição de percepções precedentes e da associação de algumas circunstâncias que lhe dão mais força e parecem lhe dar mais realidade. Eu tenho a percepção 'eu vi uma árvore', unida a percepção 'eu estava num certo lugar'; eu tenho aquela 'eu voltei nesse lugar e vi essa árvore' etc. Esta repetição e as circunstâncias que a acompanham formam uma nova percepção 'eu verei uma árvore todas as vezes que irei nesse lugar' e, enfim, 'há uma árvore”."

33 Turgot, Première lettre à l'abbé de... sur le système de Berkeley, in CEuvres complètes, cit., t. I, p. 186. A mesma idéia está em Condillac, Lettre du 25 juin 1752, in A. Le Sueur, Maupertuis et ses correspondants, Slatkine, Genève 1971, p. 393.

${ }^{34}$ Ver, ac erca desse ponto, as notas marginais deixadas por Voltaire em seu exemplar dos Dialogues entre Hylas et Philonous de Berkeley, editadas no Corpus des notes marginales de Voltaire, Akademie-Verlag, Berlin 1979, t. I, pp. 296-297.

35 Gabriel Gauchat, Lettres critiques ou analyse et réfutation de divers écrits modernes contre la religion, Claude Herissant, Pa ris 1756, t.V, pp. 229-234 ; Bergier, Suite de l'apologie de la religion chrétienne ou réfutation des principaux articles du Dictionnaire philosophique [1769], in CEuvres complètes de Bergier, Migne, Paris 1855, t.VIII, pp. 720-721.

36 Mérian, Sur l'identité numérique [1755], Histoire de l'Académie Royale des Sciences et BellesLettres, Haude \& Spener, Berlin 1757, p. 462 :"parece-me que se poderia antes persuadir a um homem que, ao se aproximar duas vezes uma flor ao órgão do olfato, ele sente dois odores, do

doispontos, Curitiba, São Carlos, vol. 4, n. 2, p.13-38, outubro, 2007 
que se lhe faria crer que, ao abrir e fechar os olhos, ele teria visto duas flores numericamente distintas. Ninguém duvida que tenha ouvido dois ou três sons desde que os tenha podido contar, mas não se estará igualmente de acordo que se tenha visto mais de um sino por ter voltado os olhos para ele diversas vezes. É que comumente os homens consideram os sons e os odores como emanações dos corpos sonoros e odoríferos, enquanto tomam as figuras e as cores como algo de inerente ao corpo, como algo que faz parte de seu ser, independentemente da percepção que dele temos".

37 Selle, De la réalité et de l'idéalité des objets de nos connaissances [1786-1787], Mémoires de l'Académie Royale des Sciences et Belles Lettres, Decker, Berlin 1792, p. 577.

${ }^{38} \mathrm{E}$ isso, tanto mais que, como escreve Pichon, "no sono, em meio a um profundo sonho, as sensações podem parecer realmente tão vivas, tão fortes e tão duráveis quanto no momento do despertar" (Cartel aux philosophes à quatre pattes, ou l'immatérialisme opposé au matérialisme, cit., p. 4).

39 Form ey, Essai sur les songes [1746], in Mémoires de l'Académie Royale de Berlin, Ambroise Audé, Berlin 1748, p. 317-333 ; Beausobre, Réflexions philosophiques sur les songes [1762], Histoire de l'Académie Royale des Sciences et Belles Lettres, Haude et Spener, Berlin 1769, pp. 429440.

40 Somnambulisme et somnambule, na Encyclopédie, Briasson, Paris 1765, t. XV, p. 342.

${ }^{41}$ Ver o que diz sobre isso Rousseau, para refutar Berkeley, em La Nouvelle Héloïs, VI, 7, in CEuvres complètes, NRF-Gallimard, «Pléiade», Paris 1964, t. II, p. 684.

\section{Referências bibliográficas}

BAYLE, P. 1820. Dictionnaire historique et critique. Paris: Desoer.

BAXTER, A. 1745. An Enquiry into the Nature of the Human Soul, Londres: A. Millar.

BEAUSOBRE, L. de. 1754. Le pyrrhonisme du sage, Berlin.

BERGIER. 1855. Suite de l'apologie de la religion chrétienne ou réfutation des principaux articles du Dictionnaire philosophique [1769]. In Euvres complètes de Bergier, Paris: Migne, t.VIII.

BERNIER, F. 1835. Éclaircissement sur le livre de M. de la Ville, repris dans les ouvres philosophiques de Descartes, Paris: Garnier.

BOULLIER. 1737. Essai philosophique sur l'âme des bêtes, Amsterdam: François Changuion. 
BOUREAU-DESLANDES. 1742. Histoire critique de la philosophie où l'on traite de son origine, de ses progrès, et des diverses révolutions qui lui sont arrivées jusqu'à notre temps, Londres: Jean Nourse.

BUFFIER. 1732. Traité des premières vérités et de la source de nos jugements [1724], retomado no Cours de science sur des principes nouveaux et simples pour former le langage, l'esprit et le cour, dans l'usage ordinaire de la vie, Paris: Cavelier et Giffart.

D’ALEMBERT. 1754. Corps, in Encyclopédie, Paris: Briasson t. IV. 1821. Éléments de philosophie, chap.VI, in Euvres complètes de d'Alembert, Paris: Belin.

DESCARTES, R. 1964-1974. Euvres de Descartes, éd. Adam et Tannery, Paris: CNRS-Vrin.

DE SALES, D. 1789. De la philosophie de la nature, ou Traité de morale pour le genre humain tiré de la philosophie et fondé sur la nature, Londres.

DE TRACY, D. 1992. Dissertation sur l'existence, et sur les hypothèses de Malebranche et de Berkeley à ce sujet. In A. e H. DENEYS (éd.). Mémoire sur la faculté de penser. De la métaphysique de Kant et autres textes, Paris: Fayard.

DIDEROT, D. 1764. Pyrrhonienne ou Sceptique, in Encyclopédie, Paris: Briasson, Paris. T.XIII, col. a.

HUET. 1723. Traité philosophique de la faiblesse de l'entendement humain, Amsterdam: Henri du Sauzet.

LECREN. 1763. Principes de centitude, ou essai sur la logique, Paris: Dessain.

LELARGE DE LIGNAC. 1753. Éléments de métaphysique tirés de l'expérience, ou lettre à un matérialiste sur la nature de l'âme, Paris: Dessaint et Saillant.

MAUPERTUIS. 1768. Lettre IV, dans CEuvres de Maupertuis. Lyon: Jean-Marie Bruyset.

MCCRACKEN C. 1998. "Knowledge of the Existence of Body", in GARBER, D. and AYERS. M (ed.), The Cambridge History of 
Seventeenth-Century Philosophy, Cambridge: Cambridge University Press, t. I, pp. 624-648.

MÉRIAN. 1798. «Sur le phénoménisme de David Hume» [1793], Mémoires de l'Académie Royale des Sciences et des Belles-Lettres, Berlin: George Decker.

PAGANINI, G. 1991. Scepsi Moderna. Interpretazioni dello scetticismo da Charron a Hume, Busento, Cosenza 2003 The Return of Scepticism from Hobbes and Descartes to Bayle, Dordrecht: Kluwer.

PICHON. 1763. Cartel aux philosophes à quatre pattes, ou l'immatérialisme opposé au matérialisme, Bruxelles.

POPKIN, R. 1995. Histoire du scepticisme d'Érasme à Spinoza. Paris: Presses Universitaires de France.

1976. Scepticism in the Enlightenment, «Studies on Voltaire and the Eighteenth Century", 26 e Scepticism and Anti-Scepticism on the Latter Part of the 18th Century, in FRITZ, P.and MORTON, R. (eds.), Woman in the 18th Century and Other Essays, Toronto and Sarasota: Samuel Stevens Hakkert.

PRÉMONTVAL, (Le Guay). 1755. Le Diogène de d'Alembert, ou Diogène décent. Berlin:, Schneider.

QUESNAY. 1756. Évidence, in Encyclopédie, Paris: Briasson, Paris, t.VI. SAINT-HYACINTHE. 1743. Recherches philosophiques sur la nécessité de s'assurer par soi-même de la vérité, sur la certitude de nos connaissances et sur la nature des êtres. Rotterdam et La Haye: Alex. Johnson. 